\title{
Motivating compliance: Juvenile probation officer strategies and skills
}

Katherine Schwartz, Andrew O. Alexander, Katherine S. L. Lau, Evan D. Holloway \& Matthew C. Aalsma

\begin{abstract}
Juvenile probation officers aim to improve youth compliance with probation conditions, but questions remain about how officers motivate youth. The study's purpose was to determine which officerreported probation strategies (client-centered vs. confrontational) were associated with their use of evidence-based motivational interviewing skills. Officers $(N=221)$ from 18 Indiana counties demonstrated motivational interviewing skills by responding to scenarios depicting issues common to youth probationers. Results of a hierarchical multiple regression analysis indicated that, while officer endorsement of client-centered strategies was not associated with differential use of motivational interviewing skills, officers endorsing confrontational strategies were less likely to demonstrate motivational interviewing skills.
\end{abstract}

This is the author's manuscript of the article published in final edited form as:

Schwartz, K., Alexander, A. O., Lau, K. S., Holloway, E. D., \& Aalsma, M. C. (2017). Motivating compliance: Juvenile probation officer strategies and skills. Journal of Offender Rehabilitation, 56(1), 20-37. http://dx.doi.org/10.1080/10509674.2016.1257532 


\section{Motivating Compliance: Juvenile Probation Officer Strategies and Skills}

Sixty-four percent of all juveniles adjudicated delinquent in 2013 were ordered to serve a term of probation (Furdella \& Puzzanchera, 2015). Though probation is offered as an alternative to secure confinement, reoffending by youth on probation can frequently lead to prolonged and more serious involvement in the justice system. In a study of youth offender records in an urban mid-Atlantic county, NeMoyer and colleagues (2014) found that $52 \%$ of all youth ordered to probation over two years had violated the terms of their probation. For nearly half of the offenders with probation violations, the violation was associated with more severe sanctions and placement in a secure facility (NeMoyer et al., 2014). Juvenile probation officers (JPOs) play an important role in preventing youths' deep-end involvement in the justice system, exercising significant discretion to establish and enforce conditions of probation through their recommendations to the court (Griffin \& Torbet, 2002). JPOs are also specifically charged with addressing the criminogenic needs of youth probationers, both to limit reoffending and foster rehabilitation (Schwalbe, 2012; Vincent, Paiva-Salisbury, Cook, Guy, \& Perrault, 2012). To achieve the goals of probation, JPOs must strive to foster youth compliance with probation conditions and established treatment plans, motivating youth probationers to change their behavior in ways that will increase the offenders' chances of exiting the system (Schwalbe \& Maschi, 2011). JPOs are thus uniquely situated to improve outcomes for youth involved in the justice system (Skeem, Louden, Polaschek, \& Camp, 2007). Despite the importance of JPOs as potential change agents within the justice system, little is known about the ways in which JPOs attempt to motivate youth probationers to comply with court orders (Skeem et al., 2007). The purpose of the current study was to first identify the nature of strategies employed by JPOs to improve youth compliance. We also sought to determine which JPO compliance strategies were most often associated with JPO use of other established evidenced-based techniques, namely motivational interviewing skills. 


\section{Probation Strategies}

Past research on the characteristics of successful probation practice - meaning that youth are released from the justice system and criminal recidivism is minimized - has focused largely on the attitudes and professional orientations of justice system personnel (Leiber, Schwarze, Mack, \& Farnworth, 2002; Ward \& Kupchik, 2008). Much attention has been given to characterizing personnel dichotomously, highlighting their endorsement of treatment versus punishment orientations, such that actors in the justice system are assumed to behave as either "social workers" or "rule enforcers" in their supervision of youth in the system (Schwalbe, 2012). Research findings indicate, however, that treatment and punishment orientations are neither mutually exclusive nor inflexible as they relate to justice system personnel, nor do practices aligning with either extreme consistently predict youth outcomes (Miller, 2015). These findings have required a re-characterization of typical probation practice. Research now shows that JPOs more often meet the description of "synthetic officer" by blending elements of both care and control orientations into their work with offenders (Miller, 2015; Ward \& Kupchik, 2008). For example, Schwalbe and Maschi (2009) reported that JPOs use a wide range of strategies, including those that reflect both deterrence and counseling orientations, in their interactions with youth probationers. Along with this shift in the literature, researchers have asserted the practical importance of identifying which probation strategies- regardless of professional orientation - are most likely to prevent youth re-involvement in the system and reduce criminal recidivism (Andretta et al., 2014; Schwalbe \& Maschi, 2009).

Findings on the effectiveness of individual JPO strategies that aim to promote compliance with youth probationers are limited (Schwalbe \& Maschi, 2009), but the adult probation literature is informative. For example, probation strategies that foster "firm but fair" officer-offender relationships have been associated with increased rule compliance among adult offenders as well as greater motivation to obtain behavioral health treatment, even after controlling for offenders' recidivism risk 
(Kennealy, Skeem, Manchak, \& Eno Louden, 2012). Officer-offender relationships associated with reduced adult reoffending are also characterized by trust, encouragement of offender autonomy, and authoritative (rather than authoritarian) approaches (Kennealy et al., 2012; Skeem \& Manchak, 2008). It is notable that utilizing probation strategies of this type, which balance offender accountability and rehabilitation goals, is also inversely related to use of strictly punitive approaches with both adult and youth probationers (Schwalbe \& Maschi, 2009; Skeem et al., 2007). More research is needed to determine whether balanced probation strategies would be as effective at influencing change within adolescent offender populations.

To identify probation strategies that effectively increase youth compliance with court orders, theories of criminal rehabilitation and desistance suggest approaching youth probationers with strategies most likely to address offenders' motivations. Andrews and colleagues (2011), describing the risk-need-responsivity model, have asserted that interventions are most effective at reducing criminal recidivism when they target specific criminogenic needs of probationers who are at the highest risk of reoffending. The responsivity principle of this model dictates that effective interventions should also account for non-criminogenic factors, including an offender's individual motivations for change (Alexander, VanBenschoten, \& Walters, 2008; Andrews \& Bonta, 2010). More particular to the juvenile justice system, Schwalbe's (2012) Participation Process Model of effective probation practice similarly describes important proximal change mechanisms by which various JPO strategies should elicit youth compliance with probation requirements and prevent future offending. The model specifically highlights the importance of motivating youth to participate in the probation process and encourages probation strategies that work to increase youth motivation (Schwalbe, 2012). Evidence-based practices that draw on these principles of promoting behavioral change have been encouraged and developed for use with adolescent offenders (Alexander et al., 2008; Henggeler \& Schoenwald, 2011). Motivational interviewing is one such evidence-based practice gaining traction in criminal and juvenile justice settings. 


\section{Motivational Interviewing Skills}

Motivational interviewing is a person-centered, collaborative style of communication between a practitioner and client, which was developed to elicit and strengthen a client's motivation for change (Miller \& Rollnick, 2012; Miller \& Rose, 2009) and to "diminish [the client's] defenses of the status quo" (Miller \& Rollnick, 2009, p. 135). The defining skills of effective motivational interviewing, no matter the setting, include the following: 1) listening reflectively and empathically; 2) asking open-ended questions; 3) affirming and summarizing responses; and 4) encouraging client-driven discussion of change (Miller \& Rollnick, 2012). Several practical strengths of motivational interviewing lend support for incorporating its principles into juvenile probation practice: the intervention can be administered in the limited time available for meeting with probationers (Cushing, Jensen, Miller, \& Leffingwell, 2014; Walters, Alexander, \& Vader, 2008); the style of motivational interviewing is developmentally appropriate for adolescents (Feldstein \& Ginsburg, 2006); and interventions based on motivational interviewing have been well-received by youth involved in the justice system (D'Amico, Hunter, Miles, Ewing, \& Osilla, 2013; D'Amico, Osilla, \& Hunter, 2010).

While motivational interviewing was initially designed to treat substance use disorders among adults (Miller \& Rollnick, 2012), its defining skills have been applied with a variety of populations to successfully address maladaptive behaviors and encourage positive behavior change. For example, when compared to an alternative or no treatment, motivational interviewing has generally been associated with improved adult and adolescent patient outcomes over a range of clinical healthcare settings and disorders, including successful management of diabetes, asthma, obesity, as well as problematic substance use (see Cushing et al., 2014; Gayes \& Steele, 2014; Hettema, Steele, \& Miller, 2005; Jensen et al., 2011; Lundahl, Kunz, Brownell, Tollefson, \& Burke, 2010; Rubak, Sandbæk, Lauritzen, \& Christensen, 2005, for review). Motivational interviewing has also been lauded within criminal justice settings for its demonstrated effectiveness in increasing rule compliance and reducing criminal 
recidivism among adult offenders (McMurran, 2009; Walters, Vader, Nguyen, Harris, \& Eells, 2010). Though empirical studies of motivational interviewing among adolescent offenders are fewer and appear largely focused on youth with substance use disorders, motivational interviewing has been associated with both engagement in treatment programming and decreased substance use among youth involved in the juvenile justice system (D'Amico et al., 2010; Stein et al., 2006; Stein et al., 2011). For example, in one study of motivational interviewing to reduce marijuana and alcohol use by formerly incarcerated youth, compared to relaxation training, youth with low levels of depressive symptoms who participated in motivational interviewing evidenced significantly fewer reported days of substance use during three months post-intervention (Stein et al., 2011). Given the success of motivational interviewing to elicit positive behavioral change across a variety of populations, it follows that JPOs who apply the principles and skills central to motivational interviewing (i.e., reflective listening, affirmations and summarizations, open-ended questions) may effectively increase youth compliance with probation requirements.

Therefore, one goal of the present study was to determine whether JPOs across Indiana apply the basic tenets of motivational interviewing to case examples of juvenile probationers. The study was also designed to identify the probation strategies of JPOs who were more likely to use evidence-based motivational interviewing skills.

\section{METHOD}

Study participants (JPOs) were recruited from Indiana counties involved in a statewide program to implement mental health screening of juvenile offenders in detention centers (Aalsma, Schwartz, \& Perkins, 2014). Of the 20 Indiana counties that operate a detention center, 19 were involved in the screening implementation project, and 18 agreed to be included in the present study, which involved survey and interview components. A total of $258 \mathrm{JPOs}$, by virtue of their employment in one of the 18 participating counties, were eligible to complete the study's online survey. Though eligible JPOs were 
not selected randomly from the Indiana's total population of JPOs, JPOs employed in counties with a detention center receive nearly $70 \%$ of the state's annual referrals to the justice system (2014 Indiana Probation Report: Summary and Statistics, 2015).

Each JPO received a study recruitment email containing a unique web link to the study survey. JPOs were informed that survey questions would require less than an hour of their time and would ask about their opinions and beliefs related to their role as a JPO. All JPOs were assured that their survey responses would neither be shared with coworkers or supervisors, nor would have bearing on evaluations of individual employees. Regardless of each JPO's willingness to respond to the survey, all 258 eligible JPOs were provided a catered lunch during regularly scheduled countywide meetings. A research assistant brought tablet computers to these lunch meetings so that JPOs who had not yet completed the survey by email could answer the questions onsite. Onsite participants were allowed to complete the surveys in a private space to approximate the study conditions of JPOs who had previously responded to the survey using a home or office computer. The lunch meetings also served as a forum for all JPOs to ask questions about the study procedures and survey items. This study was approved by the Institutional Review Board at Indiana University-Purdue University, Indianapolis.

\section{Sample}

Of the 258 eligible JPOs, 228 (88.3\%) completed the study survey. Responses from 221 JPOs, representing 17 study counties (1-52 JPOs per county), were included in the analyses; $7(3.1 \%)$ of the participating JPOs were excluded from the sample because their responses to the study's outcome measure were incomplete or because they had not responded according to the survey instructions.

Participants were predominately female $(148,67.0 \%)$, White $(177,80.1 \%)$, under age 40 (123, $55.7 \%)$, and college-educated (100\% had a bachelor's degree). JPOs reported working in the juvenile justice system for an average of 12.6 years ( $S D=8.7$, range $0-38$ years). A total of $52(23.5 \%)$ JPOs reported serving in a management or supervisory role. At the time the surveys were completed, each 
JPO was responsible for, on average, more than 43 offenders (SD = 38.5, range 0-257). Most JPOs (185, 83.7\%) indicated that their current caseloads included only juvenile, rather than adult, offenders. A majority of JPOs (>59.0\%) reported experience supervising minimum-, medium-, and high-risk probationers. Fewer than half of all respondents indicated experience providing intensive probation supervision or working with sex offenders and high needs probationers. Thirty-one (14.0\%) JPOs reported that they did not directly supervise any offenders at the time they completed the survey. See Table 1 for a complete description of the sample.

\section{Measures}

Probation strategies (Probation Practices Assessment Survey). Study participants completed the "compliance practices" subscales of the Probation Practices Assessment Survey (PPAS; Schwalbe \& Maschi, 2009). The PPAS was designed as a self-report measure of the frequency with which JPOs use specific behavioral change strategies and approaches with a select youth probationer over the previous three months (Schwalbe \& Maschi, 2011). In the current study, JPO respondents were asked to consider probationers currently on their caseloads, rather than any specific adolescent offender. The three compliance practices subscales (15 items total) asked about JPO use of both confrontational/deterrence-oriented strategies and client-centered/rehabilitative strategies to foster and enforce youth compliance with probation requirements. The 4-item confrontation practices subscale captured JPOs' use of confrontational tactics ( $\alpha=.81$; e.g., "How often did you threaten consequences like violation of probation or detention placement?"). JPO use of client-centered techniques was measured with two subscales: a 6-item counseling practices subscale ( $\alpha=.75$; e.g., "How often did you ask the youth about how his/her current behavior is related to his/her long term goals?") and a 5-item behavioral practices subscale ( $\alpha=.80$; e.g., "How often did you offer incentives for completing tasks?"). Anchors on the 5-point response scale ranged from "never" to "always" (Schwalbe \& Maschi, 2009, 2011). In the present study, three mean scores (one per subscale) were calculated for 
each respondent. Higher mean scores indicated more frequent JPO use of either confrontational or client-centered probation strategies.

Motivational interviewing skills (Officer Responses Questionnaire). To assess the extent that JPOs used motivational interviewing skills with youth probationers, participants were asked to respond to five written scenarios in which hypothetical youth probationers made statements about common probation-related topics and challenges. The five scenarios were adapted by our research team from the Officer Responses Questionnaire (ORQ; Walters et al., 2008), which has been administered to probation officers serving adult offenders (Walters et al., 2010) and tailored for use among other juvenile corrections staff (Hohman, Doran, \& Koutsenok, 2009). When the survey was administered, participants were instructed to think about their own responses to the ORQ scenarios as if they were interacting with the described youth. JPOs were then asked to write (in one or two sentences) "the next thing you would say if you wanted to let the person know that you were listening." A similar measure was originally developed to evaluate training in motivational interviewing among mental health counselors (Miller, Hedrick, \& Orlofsky, 1991).

The ORQ scenarios described by Walters and colleagues (2008) were rewritten by our research team to better reflect topics, language, and attitudes more common to juvenile, rather than adult, probationers. See Table 2 for all adapted ORQ items. For example, an original ORQ scenario, which described an adult offender blaming his wife for instigating a domestic dispute, was changed to describe an adolescent probationer blaming a peer for starting a fistfight. Another ORQ scenario about marijuana use was included verbatim in the present study, though the listed age of the hypothetical probationer was changed. To help ensure that the adapted scenarios reflected plausible and relevant issues to local JPOs, all five adapted ORQ scenarios were reviewed by a chief, and an assistant chief, probation officer from one study county. 
Scoring. ORQ responses were coded using the 5-point ordinal scale as described by Walters and colleagues (2008). The scale was designed to indicate whether practitioner responses are consistent with the principles of effective motivational interviewing. In other words, ORQ scores should convey the extent to which a practitioner's response reflects an empathic understanding of the client's statements and would facilitate continued discussion (Walters et al., 2008).

Possible scores on each of the five ORQ items ranged from 1-5, with higher scores indicating that the response demonstrated use of motivational interviewing skills. Examples of JPO responses to ORQ survey items, and their corresponding scores, can be found in Table 3. JPO responses that are antithetical to motivational interviewing were considered "communication roadblocks" and received a score of "1." For example, JPO responses including unsolicited advice, disagreement, commands, lecturing, or threats, were classified as roadblocks, since they would likely discourage a probationer from speaking again. Any JPO response containing a communication roadblock could not receive a score greater than "1," regardless of any other content within a response. Basic affirmations of a probationer's statements, including "I'm sorry that ," or "I understand that ," were coded as " 2, " as the tenets of motivational interviewing require more than mere warmth from a practitioner (Walters et al., 2008). JPO closed questions, which would require only a "yes" or "no" response from a probationer, also received a score of "2." A score of " 3 " was given when JPO responses incorporated an open-ended question, since this type of inquiry would require elaboration by the probationer. Scores of " 4 " indicated that the JPO response restated the basic content of the hypothetical prompt, amounting to a "simple reflection" of the youth's statement. A score of "5" was given only if the JPO response paraphrased the hypothetical prompt, such that the JPO demonstrated a meaningful understanding of the youth's thoughts and feelings. If a JPO response contained multiple elements (e.g., an open-ended question and a simple reflection), it would receive the higher score (e.g., " 4 " for the simple reflection). 
Scoring reliability. Two of the study's co-authors trained to score the ORQ and practiced using the scoring system by first coding the responses of 10 JPO participants (i.e., responses to 5 ORQ scenarios from each of $10 \mathrm{JPOs}$, or 50 individual responses). After this practice, the two coders, guided by another co-author, discussed and refined the coding process to improve interrater reliability. To prevent coder drift, the two coders then independently scored, discussed, and resolved scoring discrepancies on the ORQ responses of another 50 randomly-selected participants ( 250 ORQ responses total). The third co-author served as a tie-breaker in scoring disagreements. Intraclass correlations (ICCs) were calculated to assess interrater reliability, as ICCs are a more conservative estimate than Pearson's $r$ (Miller, Yahne, Moyers, Martinez, \& Pirritano, 2004). For the first 50 practice responses scored by both coders, the single measure ICC $(0.63 ; 95 \% \mathrm{CI}[.42, .77])$ indicated "good" interrater reliability according to a scale suggested by Cicchetti (1994) for evaluating reliability in clinical instruments. The ICCs [95\% Cl] for ORQ scenarios 1-5, respectively (.92 [.86, .95]; .99 [.98, .99]; .94 [.90, .97]; .89 [.81, .94]; .97 [.95, .98]) fell within the excellent range. The ICC (.94; 95\% CI [.93-.96]) for all 250 items scored by both coders was also excellent.

JPO characteristics. As in other studies of JPO practices (Andretta et al., 2014; Leiber et al., 2002; Schwalbe \& Maschi, 2011; Ward \& Kupchik, 2008), to control for other potential predictors of both JPO motivational interviewing skills and compliance strategies, participating JPOs were asked to report their gender, race, ethnicity, age group, and highest level of education completed. Additionally, participants provided the number of years they were employed in their current position as a JPO.

JPOs also reported their county of employment. Counties were categorized by level of urbanicity to account for potential variation in JPO practices and skills associated with county-specific training or procedures. More populous, urban counties may, for example, devote more resources than rural counties to provide JPOs with training in evidence-based practices, including formal training in motivational interviewing. Thus, study counties were categorized on a 5-point scale of urbanicity $(1=$ 
rural/micropolitan; $5=$ urban/large metro area) based on criteria devised by the National Center for Health Statistics (Ingram \& Franco, 2014). For the purposes of this study, counties with urbanicity ratings of $\geq 3$ (i.e., $\geq 250,000$ population) were classified as urban, and counties with ratings of $1-2$ (i.e., $<250,000$ population) were classified as rural.

To confirm that participating JPOs did, in fact, have experience with a range of common probation-related topics and types of adolescent probationers, respondents were asked whether their caseloads included minimum-, medium-, and high-risk youth; sex offenders; or high-needs probationers. JPOs also reported their caseload size and whether they currently supervised youth, supervised any adults, or provided intensive probation supervision.

Analysis. Hierarchical multiple regression was performed to test whether JPO endorsement of specific probation strategies predicted JPO use of skills consistent with principles of motivational interviewing. Preliminary analyses were conducted to ensure no violation of model assumptions, which included a review of intercorrelations and tests for multicollinearity among predictor variables. To control for the effects of individual JPO characteristics on ORQ scores, Step 1 predictors included control variables: JPO age, race (dummy coded as minority vs. White), and gender. Step 1 also included the urbanicity of the county in which JPOs were employed (urban vs. rural), total years of employment in the juvenile justice system, and highest level of education completed. JPO probation strategies, reflected in their scores on the three compliance strategy subscales of the PPAS, were entered into Step 2. Mean JPO scores on the ORQ, a measure of their use of motivational interviewing skills, served as the dependent variable.

\section{RESULTS}

Descriptive findings on the PPAS compliance practices subscales, and on the ORQ measure of motivational interviewing skills, are reported in Table 4. The mean PPAS subscale score of JPO use of confrontation strategies was $2.22(\mathrm{SD}=.74)$ on the $0-4$ scale. The mean score on the client-centered 
strategies was: $1.70(\mathrm{SD}=.68)$ on counseling; $1.94(\mathrm{SD}=.67)$ on behavioral strategies. Of possible ORQ scores ranging from 1-5, the mean total score was $2.01(S D=0.99 ;$ mode $=1.00)$. Mean ORQ scores on individual scenarios follow in the order of the items presented in Table 2: 2.11 (SD =1.16); 1.95 (SD = $1.30) ; 2.13(\mathrm{SD}=1.32) ; 2.04(\mathrm{SD}=1.27) ;$ and $1.81(\mathrm{SD}=1.14)$.

The intercorrelations among all variables included in the hierarchical regression model are also presented in Table 4. The outcome variable, JPO scores on the ORQ measure of motivational interviewing skills, was significantly related to both the gender $(r=.21, p=.001)$ and race $(r=.14, p=$ .022) of the JPO respondent. Additionally, all JPO compliance strategies, as measured by scores on the PPAS, were significantly related to scores on the ORQ, which lent support for testing the predictive value of these variables: Confrontation $(r=-.14, p=.018)$; Counseling $(r=.13, p=.028)$; Behavioral $(r=.171, p$ $=.005)$. Any significant correlations among the predictor variables were generally weak to moderate, with most $r$ values ranging from $.12(p<.05)$ to $.23(p<.001)$. In contrast, JPO age and the number of years they were employed in the juvenile justice system were strongly related $(r=.76, p<.001)$. Scores on the PPAS compliance strategy subscales were also highly related, with all $r$ values greater than .51 ( $p$ $<.001)$. However, tests for multicollinearity yielded VIF values of less than 2.5 for all variables, indicating that the low level of multicollinearity present in the model should not be problematic (O'Brien, 2007) (see Table 5).

Results of the hierarchical regression analysis are presented in Table 5. Step 1 of the model, which included JPO respondent characteristics, significantly predicted JPO scores on motivational interviewing skills as measured by the $\operatorname{ORQ}[F(6,213)=4.24 ; p<.001]$ and accounted for $11 \%$ of the variance in scores. After JPO scores on the PPAS compliance strategy subscales were added in Step 2, the model captured $21 \%$ of the variance in ORQ scores $[F(9,210)=6.08 ; p<.001]$. The additional $10 \%$ explained by the PPAS scores was a statistically significant improvement in model fit $[F(3,210)=8.83 ; p$ $<.001)$ ]. In the final model, most JPO characteristics significantly predicted motivational interviewing 
skill scores on the ORQ, with the exception of JPO age and county urbanicity (see Table 5 for all Beta values). Of the PPAS subscale scores measuring JPO strategies, JPO scores on the ORQ were predicted only by scores on the confrontation subscale $(\beta=-.36, p<.001)$.

\section{DISCUSSION}

Previous research has demonstrated that probation officers tend to employ a range of strategies to increase probationer compliance with court orders (Schwalbe \& Maschi, 2009, 2011). Further, strategies that blend professional orientations of both care and control, rather than purely punitive approaches, appear mostly likely to reduce recidivism (Kennealy, Skeem, Manchak, \& Eno Louden, 2012). Among evidence-based interventions, motivational interviewing has been show to effectively promote behavioral change across a variety of populations and settings (Cushing et al., 2014; Jensen et al., 2011). Among adult offenders, the principles of motivational interviewing - embodied by a practitioner's use of reflective listening, open-ended questions, and affirmations - have been associated with rule compliance and reduced criminal recidivism (McMurran, 2009). Though empirical tests of motivational interviewing with youth offender outcomes are relatively few, employing motivational interviewing skills in the juvenile justice system has also garnered theoretical support (Schwalbe, 2012). Therefore, the aims of the current study were to identify the compliance strategies utilized by JPOs with adolescent probationers and to determine which strategies were most often associated with evidencebased motivational interviewing skills.

Variation in JPO use of compliance strategies as measured by the PPAS was significantly associated with their differential use of motivational interviewing skills, and JPO strategies predicted use of motivational interviewing above and beyond the influence of individual JPO characteristics. Specifically, frequent endorsement of confrontational probation strategies (i.e., threatening consequences) was predictive of lower scores on the ORQ, or less use of effective motivational interviewing skills. In contrast, it appeared that both counseling and behavioral strategies (client- 
centered probation tactics) were not significantly associated with the core skills of motivational interviewing.

Study findings are consistent with past research of both probation strategies and therapeutic practices, which shows that confrontational tactics thwart practitioner-client collaboration and rapport and, instead, contribute to resistance to change (Miller \& Wilbourne, 2002; Schwalbe \& Maschi, 2009). Though JPO endorsement of client-centered strategies was not related to use of effective motivational interviewing skills in the current study, JPOs did report practicing a range of many tactics with youth probationers. This is similar to past research findings, which suggest that JPOs may differ by the total number of strategies they use, not the type. In other words, JPOs who have reported using many clientcentered approaches also reported using roughly the same amount of confrontational approaches, while other JPOs reported little use of either type of strategy (Schwalbe \& Maschi, 2009, 2011).

Overall, regardless of JPOs' individual characteristics and their endorsement of specific probation strategies, survey respondents exhibited very little use of motivational interviewing skills. The mean score across all five ORQ scenarios (2.01), and the mean scores on individual ORQ items, were roughly equivalent to a JPO responding with a basic affirmation of the probationer's feelings, a closed question, an offer of help, or another non-reflective response. A JPO response receiving this score indicates a wasted opportunity to elicit more essential information from youth and promote youth participation (Walters et al., 2008; Walters et al., 2010). More problematic is that the score most commonly assigned to any ORQ response was "1," (i.e., a communication roadblock), suggesting that not only were JPOs failing to demonstrate motivational interviewing skills, their responses were wholly antithetical to effective motivational interviewing principles.

Limitations. There are some limitations to interpreting the results of this study. For example, study measures did not capture the extent to which JPOs received any type of training, formal or informal, in motivational interviewing or related skills. Training may have differentially impacted JPO 
scores on both the PPAS and ORQ. Furthermore, it was not possible to observe youth probationers to assess the influence of JPO compliance strategies and motivational interviewing skills on youth outcomes. JPOs were given a hypothetical set of scenarios and asked to provide written responses, which may leave out important cues about JPO tone and body language and affect coder scoring of motivational interviewing using the ORQ. The outcome measure, the ORQ, captured only a subset of motivational skills and should not be considered an assessment of all components required of effective motivational interviewing (Walters et al., 2008). While the current study's findings did not demonstrate whether JPOs actually employ specific strategies and skills with their probationers, it was possible to observe the capacity of JPOs to provide reflective and empathetic responses to youth offenders (Walters et al., 2008).

\section{CONCLUSIONS}

The study findings present potential opportunities to improve JPO probation practices. For example, because we found that JPOs who use confrontational strategies are less likely to use evidencebased motivational interviewing skills, JPO trainings should dissuade participants from over-utilizing these approaches with youth probationers. An initial assessment of JPOs' preferred probation strategies may help tailor subsequent trainings to JPO styles and individual needs for improvement. It also appears that JPOs might benefit from learning the core skills of motivational interviewing, such as reflective listening and affirming statements, given that the responses of JPO participants frequently contained roadblocks to continued conversation. Beyond the practical implications of the study findings, additional research is needed to confirm the effectiveness of motivational interviewing to influence youth offenders. While there is significant theoretical support for implementing motivational interviewing with youth in the juvenile justice system - and there is evidence that the intervention is associated with behavioral change among adults - future studies should examine whether motivational interviewing promotes sustained reductions in criminal recidivism among adolescent offenders. Further study of 
evidence-based interventions tailored specifically to adolescent populations, including additional study of motivational interviewing, may provide an opportunity for JPOs to increase youth compliance with probation conditions and engagement in services that may ultimately prevent deep-end involvement in the justice system. Given the unique role of JPOs to effect behavior change within the system, our findings should encourage efforts to determine whether improving JPO competence in motivational interviewing skills improves youth probationer outcomes. 


\section{References}

2014 Indiana Probation Report: Summary and Statistics. (2015). Indianapolis, IN: Division of State Court Administration. Available at http://www.in.gov/judiciary/admin/files/rpts-ijs-2014-probationv1-summary.pdf. Accessed May 18, 2016.

Aalsma, M. C., Schwartz, K., \& Perkins, A. J. (2014). A statewide collaboration to initiate mental health screening and assess services for detained youths in Indiana. American Journal of Public Health, 104(10), e82-e88.

Alexander, M., VanBenschoten, S. W., \& Walters, S. T. (2008). Motivational interviewing training in criminal justice: Development of a model plan. Federal Probation, 72(2), 61-66,91.

Andretta, J. R., Odom, T., Barksdale, F., Barnes, M. E., Ramirez, A. M., \& Woodland, M. H. (2014). An examination of management strategies and attitudes among probation officers. Journal of Forensic Social Work, 4(2), 150-166.

Andrews, D. A., \& Bonta, J. (2010). Rehabilitating criminal justice policy and practice. Psychology, Public Policy, and Law, 16(1), 39-55.

Andrews, D. A., Bonta, J., \& Wormith, J. S. (2011). The Risk-Need-Responsivity (RNR) Model: Does adding the Good Lives Model contribute to effective crime prevention? Criminal Justice and Behavior, 38(7), 735-755.

Cicchetti, D. V. (1994). Guidelines, criteria, and rules of thumb for evaluating normed and standardized assessment instruments in psychology. Psychological Assessment, 6(4), 284-290.

Cushing, C. C., Jensen, C. D., Miller, M. B., \& Leffingwell, T. R. (2014). Meta-analysis of motivational interviewing for adolescent health behavior: efficacy beyond substance use. Journal of Consulting and Clinical Psychology, 82(6), 1212-1218. 
D'Amico, E. J., Hunter, S. B., Miles, J. N., Ewing, B. A., \& Osilla, K. C. (2013). A randomized controlled trial of a group motivational interviewing intervention for adolescents with a first time alcohol or drug offense. Journal of Substance Abuse Treatment, 45(5), 400-408.

D'Amico, E. J., Osilla, K. C., \& Hunter, S. B. (2010). Developing a group motivational interviewing intervention for first-time adolescent offenders at-risk for an alcohol or drug use disorder. Alcoholism Treatment Quarterly, 28(4), 417-436.

Feldstein, S. W., \& Ginsburg, J. I. (2006). Motivational interviewing with dually diagnosed adolescents in juvenile justice settings. Brief Treatment and Crisis Intervention, 6(3), 218.

Furdella, J., \& Puzzanchera, C. (2015). Delinquency cases in juvenile court, 2013. Juvenile Offenders and Victims: National Report Series, October.

Gayes, L. A., \& Steele, R. G. (2014). A meta-analysis of motivational interviewing interventions for pediatric health behavior change. Journal of Consulting and Clinical Psychology, 82(3), 521-535.

Griffin, P., \& Torbet, P. (Eds.). (2002). Desktop Guide to Good Juvenile Probation Practice. National Center for Juvenile Justice.

Henggeler, S., \& Schoenwald, S. J. (2011). Evidence-based interventions for juvenile offenders and juvenile justice policies that support them. Social Policy Report, 25(1), 1-20.

Hettema, J., Steele, J., \& Miller, W. R. (2005). Motivational interviewing. Annual Review of Clinical Psychology, 1, 91-111.

Hohman, M., Doran, N., \& Koutsenok, I. (2009). Motivational interviewing training for juvenile correctional staff in California: One year initial outcomes. Journal of Offender Rehabilitation, $48(7), 635-648$.

Ingram, D., \& Franco, S. (2014). 2013 NCHS urban-rural classification scheme for counties. National Center for Health Statistics. Vital and Health Statistics. Series 2: Data Evaluation and Methods Research, 166. 
Jensen, C. D., Cushing, C. C., Aylward, B. S., Craig, J. T., Sorell, D. M., \& Steele, R. G. (2011). Effectiveness of motivational interviewing interventions for adolescent substance use behavior change: $\mathrm{A}$ meta-analytic review. Journal of Consulting and Clinical Psychology, 79(4), 433-440.

Kennealy, P. J., Skeem, J. L., Manchak, S. M., \& Eno Louden, J. (2012). Firm, fair, and caring officeroffender relationships protect against supervision failure. Law and Human Behavior, 36(6), 496505.

Leiber, M. J., \& Peck, J. H. (2013). Probation violations and juvenile justice decision making: Implications for Blacks and Hispanics. Youth Violence and Juvenile Justice, 11(1), 60-78.

Leiber, M. J., Schwarze, K., Mack, K. Y., \& Farnworth, M. (2002). The effects of occupation and education on punitive orientations among juvenile justice personnel. Journal of Criminal Justice, 30(4), 303316.

Lundahl, B. W., Kunz, C., Brownell, C., Tollefson, D., \& Burke, B. L. (2010). A meta-analysis of motivational interviewing: Twenty-five years of empirical studies. Research on Social Work Practice, 20(2), 137-160.

McMurran, M. (2009). Motivational interviewing with offenders: A systematic review. Legal and Criminological Psychology, 14(1), 83-100.

Miller, J. (2015). Contemporary Modes of Probation Officer Supervision: The Triumph of the "Synthetic" Officer? Justice Quarterly, 32(2), 314-336.

Miller, W. R., Hedrick, K. E., \& Orlofsky, D. R. (1991). The Helpful Responses Questionnaire: A procedure for measuring therapeutic empathy. Journal of Clinical Psychology, 47(3), 444-448.

Miller, W. R., \& Rollnick, S. (2009). Ten things that motivational interviewing is not. Behavioural and Cognitive Psychotherapy, 37, 129-140.

Miller, W. R., \& Rollnick, S. (2012). Motivational Interviewing: Helping People Change (3rd ed.) New York: The Guilford Press. 
Miller, W. R., \& Rose, G. S. (2009). Toward a theory of motivational interviewing. The American Psychologist, 64(6), 527-537.

Miller, W. R., \& Wilbourne, P. L. (2002). Mesa Grande: a methodological analysis of clinical trials of treatments for alcohol use disorders. Addiction, 97(3), 265-277.

Miller, W. R., Yahne, C. E., Moyers, T. B., Martinez, J., \& Pirritano, M. (2004). A randomized trial of methods to help clinicians learn motivational interviewing. Journal of Consulting and Clinical Psychology, 72(6), 1050-1062.

NeMoyer, A., Goldstein, N. E. S., McKitten, R. L., Prelic, A., Ebbecke, J., Foster, E., \& Burkard, C. (2014). Predictors of juveniles' noncompliance with probation requirements. Law and Human Behavior, $38(6), 580-591$.

O'Brien, R. M. (2007). A caution regarding rules of thumb for variance inflation factors. Quality \& Quantity, 41, 673-690.

Rubak, S., Sandbæk, A., Lauritzen, T., \& Christensen, B. (2005). Motivational interviewing: a systematic review and meta-analysis. The British Journal of General Practice, 55(513), 305-312.

Schwalbe, C. S. (2012). Toward an integrated theory of probation. Criminal Justice and Behavior, 39(2), 185-201.

Schwalbe, C. S., \& Maschi, T. (2009). Investigating probation strategies with juvenile offenders: the influence of officers' attitudes and youth characteristics. Law and Human Behavior, 33(5), 357367.

Schwalbe, C. S., \& Maschi, T. (2011). Confronting delinquency: Probations officers' use of coercion and client-centered tactics to foster youth compliance. Crime \& Delinquency, 57(5), 801-822.

Skeem, J. L., Louden, J. E., Polaschek, D., \& Camp, J. (2007). Assessing relationship quality in mandated community treatment: blending care with control. Psychological Assessment, 19(4), 397. 
Skeem, J. L., \& Manchak, S. (2008). Back to the future: From Klockars' model of effective supervision to evidence-based practice in probation. Journal of Offender Rehabilitation, 47(3), 220-247.

Stein, L. A. R., Colby, S. M., Barnett, N. P., Monti, P. M., Golembeske, C., Lebeau-Craven, R., \& Miranda, R. (2006). Enhancing substance abuse treatment engagement in incarcerated adolescents. Psychological Services, 3(1), 25-34.

Stein, L. A. R., Lebeau, R., Colby, S. M., Barnett, N. P., Golembeske, C., \& Monti, P. M. (2011). Motivational interviewing for incarcerated adolescents: Effects of depressive symptoms on reducing alcohol and marijuana use after release. Journal of Studies on Alcohol and Drugs, 72(3), 497-506.

Vincent, G. M., Paiva-Salisbury, M. L., Cook, N. E., Guy, L. S., \& Perrault, R. T. (2012). Impact of risk/needs assessment on juvenile probation officers' decision making: Importance of implementation. Psychology, Public Policy, and Law, 18(4), 549-576.

Walters, S. T., Alexander, M., \& Vader, A. M. (2008). The Officer Responses Questionnaire: A procedure for measuring reflective listening in probation and parole settings. Federal Probation, 72(2), 6770.

Walters, S. T., Vader, A. M., Nguyen, N., Harris, T. R., \& Eells, J. (2010). Motivational interviewing as a supervision strategy in probation: A randomized effectiveness trial. Journal of Offender Rehabilitation, 49(5), 309-323.

Ward, G., \& Kupchik, A. (2008). What drives juvenile probation officers?: Relating organizational contexts, status characteristics, and personal convictions to treatment and punishment orientations. Crime \& Delinquency, 56(1), 35-69. 


\begin{tabular}{|c|c|c|}
\hline JPO Demographics & & $n(\%)$ \\
\hline \multirow[t]{2}{*}{ Gender } & Male & $73(33.0)$ \\
\hline & Female & $148(67.0)$ \\
\hline \multirow[t]{4}{*}{ Race/ethnicity } & White & $177(80.1)$ \\
\hline & Black & 33 (14.9) \\
\hline & Hispanic & $5(2.3)$ \\
\hline & Other & $6(2.7)$ \\
\hline \multirow[t]{5}{*}{ Age (years) } & $20-29$ & $39(17.6)$ \\
\hline & $30-39$ & $84(38.0)$ \\
\hline & $40-49$ & $60(27.1)$ \\
\hline & $50-59$ & $36(16.3)$ \\
\hline & 60 and older & $2(0.9)$ \\
\hline \multirow[t]{3}{*}{ Highest education level } & 4-year college & $156(70.6)$ \\
\hline & Some graduate school & $31(14.0)$ \\
\hline & Master's degree & $34(15.4)$ \\
\hline \multirow[t]{2}{*}{ County of employment } & Rural & $70(31.7)$ \\
\hline & Urban & $151(68.3)$ \\
\hline \multicolumn{3}{|l|}{ JPO Job Characteristics } \\
\hline Role & Manage other JPOs & $152(23.5)$ \\
\hline & $\begin{array}{l}\text { Supervise juvenile (vs. adult) } \\
\text { probationers only }\end{array}$ & $185(83.7)$ \\
\hline \multirow[t]{7}{*}{$\begin{array}{l}\text { Client types supervised } \\
\text { (not mutually exclusive) }\end{array}$} & Minimal risk & $141(63.8)$ \\
\hline & Medium Risk & $142(64.3)$ \\
\hline & High Risk & $131(59.3)$ \\
\hline & High needs & $99(44.8)$ \\
\hline & Intensive supervision & $65(29.4)$ \\
\hline & Sex offenders & $69(31.2)$ \\
\hline & None & $\begin{array}{l}31(14.0) \\
\text { Mean (SD) } \\
\text { range }\end{array}$ \\
\hline \multirow[t]{2}{*}{ Years employed } & In juvenile justice system & $\begin{array}{l}12.6(8.7) \\
0-38\end{array}$ \\
\hline & As a JPO & $\begin{array}{l}7.73(6.68) \\
0-32\end{array}$ \\
\hline Caseload size & $\begin{array}{r}\text { Number of youth } \\
\text { probationers }\end{array}$ & $\begin{array}{l}43.3(38.5) \\
0-257\end{array}$ \\
\hline
\end{tabular}


Table 2. Officer Response Questionnaire items, adapted to describe youth probationers

Item 1: A 13-year old tells you: "The reason I keep skipping my Math class is because my teacher is always getting pissed at me for not paying attention. It's because I don't understand the stuff he's talking about. He embarrassed me in front of the class the other day, so I'm not going back to his class."

Item 2: A 15-year-old tells you: “The rules at my grandma's house don't make sense. She told me I have to be home at $10 \mathrm{pm}$, but my cousin gets to come home whenever she wants. That $\mathrm{s}^{* *} \mathrm{t}$ isn't fair, so I don't really care what she says."

Item 3: A 17-year-old tells you: "Every time I hang out with Robert I get into trouble. I know I'm not supposed to hang out with him, but he's been my best friend since I was four and he lives right next door."

Item 4: A 14-year-old tells you: "What was I supposed to do, get my a** beat?! He threw the first punch. I was just defending myself. I can't believe I'm in trouble for this. If it happened all over again, I would still whoop him."

Item 5: A 12-year-old says: "I like to smoke weed. The way I see it, I never hurt anyone, so people should just leave me alone. I'll stay clean while I'm on probation, but after I'm off, I'm going to do what I want." 
Table 3. Example scoring of JPO responses to the Officer Response Questionnaire

Prompt: A 13-year old tells you: "The reason I keep skipping my math class is because my teacher is always getting pissed at me for not paying attention. It's because I don't understand the stuff he's talking about. He embarrassed me in front of the class the other day so I'm not going back to his class."

Example JPO Responses Score

"You HAVE to go to class! How about you go up to your teacher after class and tell him that?"

1

communication

roadblock

"I'm sorry that math is so hard for you. Let's meet with the teacher and your mom at the school."

2

basic

affirmation/help

3

"I get it. What are your options for going forward for this school year?"

"You've been having some trouble in your math class, and that is why you have not been attending regularly. Let's talk about what we can do about this situation."

open-ended question

4 simple reflection

"So, you might go to class if the teacher was more understanding, but for now it's too embarrassing."

5 complex reflective 
Table 4: Correlations and descriptives for continuous variables included in hierarchal regression model $(N=220)$

\begin{tabular}{|c|c|c|c|c|c|c|c|c|c|c|}
\hline & ORQ & County & Age & Race & Gender & Edu & JJ Yrs & Confront & Counsel & Behav \\
\hline ORQ Score & - & - & - & - & - & - & - & - & - & - \\
\hline County Urbanicity & .04 & - & - & - & - & - & - & - & - & - \\
\hline Age & -.05 & -.04 & - & - & - & - & - & - & - & - \\
\hline Race & $.14^{*}$ & $-.14^{*}$ & .01 & - & - & - & - & - & - & - \\
\hline Gender & $.21 * *$ & -.09 & -.10 & -.10 & - & - & - & - & - & - \\
\hline Highest Education & .10 & .06 & $.12^{*}$ & -.07 & -.02 & - & - & - & - & - \\
\hline Years in JJ system & -.10 & -.04 & $.76 * * *$ & .08 & -.06 & $.15^{*}$ & - & - & - & - \\
\hline \multicolumn{11}{|l|}{$\begin{array}{l}\text { PPAS: Compliance Strategies } \\
\text { Subscale Scores }\end{array}$} \\
\hline Confrontation & $-.14^{*}$ & $.22 * *$ & $-.13^{*}$ & $-.14^{*}$ & .07 & .08 & -.09 & - & - & - \\
\hline Counseling & $.13^{*}$ & $.23 * * *$ & .02 & -.10 & .09 & .07 & .08 & $.53 * * *$ & - & - \\
\hline Behavioral & $.17 * *$ & $.17 * *$ & -.01 & -.08 & $.20 * *$ & .08 & .04 & $.51 * * *$ & $.74 * * *$ & - \\
\hline Mean & 2.01 & - & - & - & - & - & - & 2.22 & 1.70 & 1.94 \\
\hline Standard Deviation & .99 & - & - & - & - & - & - & .74 & .68 & .67 \\
\hline Range & $1-4.6$ & - & - & - & - & - & - & $0-4$ & $0-3.5$ & $.2-4$ \\
\hline Possible Range & $1-5$ & - & - & - & - & - & - & $0-4$ & $0-4$ & $0-4$ \\
\hline
\end{tabular}

$* p<.05 ; * * p<.01 ; * * *<.001$

ORQ = Officer Response Questionnaire

PPAS = Probation Practice Assessment Survey 


\begin{tabular}{|c|c|c|c|c|c|}
\hline Model & $R^{2}$ & $R^{2}$ change & $\beta$ & $t$ & VIF \\
\hline Step 1: JPO Characteristics & $.11^{* * *}$ & & & & \\
\hline County Urbanicity & & & .08 & 1.26 & 1.11 \\
\hline Age & & & .08 & 0.84 & 2.43 \\
\hline Race & & & $.18 * *$ & 2.78 & 1.07 \\
\hline Gender & & & $.21^{* *}$ & 3.19 & 1.09 \\
\hline Highest education level & & & $.14^{*}$ & 2.16 & 1.04 \\
\hline Years in juvenile justice system & & & $-.23 *$ & -2.42 & 2.45 \\
\hline $\begin{array}{l}\text { Step 2: PPAS Compliance Strategies } \\
\text { Subscale Scores }\end{array}$ & $.21 * * *$ & $.10 * * *$ & & & \\
\hline Confrontation & & & $-.36 * * *$ & -4.66 & 1.54 \\
\hline Counseling & & & .17 & 1.81 & 2.43 \\
\hline Behavioral & & & .18 & 1.91 & 2.37 \\
\hline
\end{tabular}

${ }^{*} p<.05 ;{ }^{* *} p<.01 ;{ }^{* * *} p<.001$

County Urbanicity: Rural $=0$, Urban $=1$

Race: Minority $=0$, White $=1$

Gender: Male $=0$, Female $=1$ 